\title{
Biological Parameters of Spodoptera frugiperda (J. E. Smith) under Laboratory Conditions
}

\author{
Deepika Kalyan $^{1 *}$, M. K. Mahla ${ }^{1}$, S. Ramesh Babu ${ }^{2}$, R. K. Kalyan ${ }^{2}$ and P. Swathi ${ }^{1}$ \\ ${ }^{1}$ Department of Entomology, Rajasthan College of Agriculture, Maharana Pratap University \\ of Agriculture and Technology (MPUAT), Udaipur, Rajasthan, India \\ ${ }^{2}$ Agricultural Research Station, Maharana Pratap University of Agriculture and Technology \\ (MPUAT), Borwat Farm, Banswara, Rajasthan, India \\ *Corresponding author
}

\section{A B S T R A C T}

\begin{tabular}{l} 
Ke y w o r d s \\
Spodoptera \\
frugiperda, Fall \\
armyworm, \\
Biology, \\
Morphometrics, \\
Maize \\
\hline Article Info \\
\hline $\begin{array}{l}\text { Accepted: } \\
\text { 23 April } 2020 \\
\text { Available Online: } \\
\text { 10 May } 2020\end{array}$ \\
\hline
\end{tabular}

The fall armyworm, Spodoptera frugiperda (J. E. Smith) is a highly notorious lepidopteran pest which is causing severe economic loss in different crops, especially maize. A study was conducted to know the biology of S. frugiperda on maize during July-December, 2019 under laboratory conditions at the Department of Entomology, Rajasthan College of Agriculture, MPUAT, Udaipur. The mean incubation, larval, pupal, preoviposition, oviposition and post-oviposition period were observed to be $3.30,16.97,8.96,3.47,2.96$ and 6.13 days, respectively. The mean adult longevity of male and female was 10.67 and 13.00 days. The mean total life cycle was recorded to be 37.68 days. The average fecundity was 1662 eggs. Various morphometric data were also recorded.

\section{Introduction}

Spodoptera frugiperda (J. E. Smith) (Lepidoptera: Noctuidae) or commonly known as fall armyworm is a native of tropical and subtropical regions of America. Till 2016, FAW was constrained to its native region of origin. However, in this year, it was reported from Africa causing serious damage to the maize crops (Goergen et al., 2016) and since then has spread across most of the subSaharan Africa. In about three years it reached to another continent, Asia. In 2018, it was first time reported from India in Karnataka (Sharanabasappa et al., 2018).

Since then, it has been reported from many states in India (CABI, 2019) on different crops like maize, sugarcane and sorghum. But, in our country it has caused substantial 
damage to maize crop (Chimweta et al., 2019). It is clear that fall armyworm is a major threat to maize crop and hence a complete knowledge of its biology and morphology becomes very important to formulate proper management techniques against this pest. Keeping in view these facts, the biology of FAW on maize was studied under laboratory conditions.

\section{Materials and Methods}

\section{Larvae collection and identification}

To study the biology of $S$. frugiperda, its larvae were collected from the maize fields at RCA, Udaipur to start the culture. They were identified by studying their various morphological characters and also by DNA barcoding method. For molecular identification, the total genomic DNA was extracted from the collected larvae using DNASure Tissue mini kit (Nucleo-pore, Genetix Brand, India), in accordance with the manufacturer's instructions. PCR amplification of COI (cytochrome oxidase subunit I) gene of $658-700 \mathrm{bp}$ region was carried out for an initial denaturation of $94^{\circ} \mathrm{C}$ for $4 \mathrm{~min}$, followed by 35 cycles of denaturation at $94^{\circ} \mathrm{C}$ for $30 \mathrm{sec}$, annealing at $47^{\circ} \mathrm{C}$ for $45 \mathrm{sec}$, extension at $72^{\circ} \mathrm{C}$ for $45 \mathrm{sec}$ and final extension at $72^{\circ} \mathrm{C}$ for $20 \mathrm{~min}$., using the universal primers viz., forward primer: (LCO1490 5'-GGTCAACAAATCAT AAAGATATTGG-3') and reverse primer: (HCO2198 5'-TAAACTTCAGGGTGAC CAAAAAATCA3'). The amplified and purified PCR product was sent through outsourcing Agile Lifescience Technologies India Pvt. Ltd, Pune (ABI PRISM 3730xl Genetic Analyzer develop by Applied Biosystems, USA) for sequencing target fragment by using universal primers. The obtained chromatogram was edited to remove the ambiguous bases and the sequence was compared with authenticated sequences through Basic Local Alignment Search Tool (BLASTn, http://www.ncbLn1m.nih.gov) search to confirm the identity of the sequence. The sequence obtained was deposited at the gene bank of National Center for Biotechnology Information (NCBI), USA to obtain the accession number.

\section{Biology of FAW}

The biology of $S$. frugiperda was studied in the laboratory under controlled conditions of $25 \pm 2^{\circ} \mathrm{C}$ and $70-75 \% \mathrm{RH}$. The culture was maintained in glass jars and provided fresh maize leaves and stem, of variety Pratap Makka-3, daily until pupation. The pupae so developed were transferred into clean jars until the emergence of moths. The adults that emerged were paired and allowed to mate in separate mating cages. The moths were fed with $10 \%$ honey solution soaked on cotton pads for proper egg laying. The eggs thus laid were used for the experiment. After hatching, the larvae were transferred into new glass jars and reared individually on fresh maize leaves which were changed daily as food. To study the biology, the observations on different biological parameters viz., incubation period, larval period, pupal period, pre-oviposition period, oviposition period, post-oviposition period, adult male and female longevity, total life cycle and fecundity were recorded. Four generations were maintained and mean observations were taken. Necessary morphological traits were also measured such as: length of larval instars, pupae, adults and their wing span.

\section{Results and Discussion}

\section{Morphological identification}

Diagnostic characters of FAW such as the black spots arranged in a square pattern on the $8^{\text {th }}$ abdominal segment and in a trapezoidal pattern on $1^{\text {st }}$ to $7^{\text {th }}$ abdominal segments of the 
larvae (Fig. 1a), an inverted "Y" shape on the larval head capsule (Fig. 1b) and reddish brown pupae with characteristic cremaster with two spines (Fig. 1c) were observed. The male moths had grey to brown coloured forewings with a reniform indistinct spot at the junction of $\mathrm{M} 3$ and $\mathrm{CuA} 1$ veins and a triangular white patch near the apical margins (Fig. 1d), while the female moths had more uniformly coloured forewings (Fig. 1e). These characters were confirmed with earlier findings of Pogue, 2002 and EPPO, 2015.

\section{Molecular identification}

The search analysis in the BLAST identified the insect species as $S$. frugiperda with a GenBank accession number of MN117927.

\section{Biology of FAW}

\section{Egg}

The eggs were laid in egg masses and the number of eggs per mass was 25-330. The egg masses laid by a gravid female ranged from 4-11. The eggs were pale white to creamish in colour covered with grayish white scales of the female abdomen (Fig. 2) The colour of the eggs turned brown to black just before hatching. The eggs took 3-4 days to hatch, with a mean time of 3.30 days (Table 1).

\section{Larva}

\section{First instar}

The $1^{\text {st }}$ larval instars were very tiny. They completely devoured the egg shells from which they hatched. They had a comparatively large flattened circular black head and a whitish body covered with minute hairs (Fig. 3). The mean development time of the first larval instar was 2.8 days (Table 1).

\section{Second instar}

The $2^{\text {nd }}$ instar larvae had amber coloured head and a pale white to yellowish coloured body with a tinge of brown on the dorsum (Fig. 4). The body also developed faint white dorsal and sub-dorsal lines at this stage. The mean development time of the second larval instar was 2.5 days (Table 1 )

\section{Third instar}

The $3^{\text {rd }}$ instar larvae showed an immense change in body colour. The body colour changed from pale white to greenish brown (Fig. 5). The dorsal and sub-dorsal white lines were plainly visible and the black spots became prominent. The mean development time of this instar was 2.5 days (Table 1 ).

\section{Fourth instar}

The body colour of $4^{\text {th }}$ instar larvae varied from olive brown to dark brown (Fig. 6). The dorsal and sub-dorsal white lines also became conspicuous. The mean development time of the $4^{\text {th }}$ larval instar was 2.0 days (Table 1 ).

\section{Fifth instar}

The body of $5^{\text {th }}$ instar larvae attained a grayish brown colour on the dorsum and greenish colour on the ventral and sub-ventral sides (Fig. 7). The mean development time of the $5^{\text {th }}$ larval instar was 2.7 days (Table 1 ).

\section{Sixth instar}

The $6^{\text {th }}$ instar larvae were most stout and bulged with somewhat cylindrical in shape. Their body was smooth with clear and distinct segmentation. The head was black and slightly bilobed. The colour of the body was grayish brown on the dorsum, while the ventral and sub-ventral sides were greenish mottled with reddish brown colour (Fig. 8). 
Table.1 Biology of S. frugiperda on maize under laboratory conditions

\begin{tabular}{|c|c|c|c|c|c|c|c|c|c|c|}
\hline \multirow{3}{*}{$\begin{array}{c}\text { S. } \\
\text { No. }\end{array}$} & \multirow[t]{3}{*}{ Life stages } & \multicolumn{8}{|c|}{ Period of study } & \multirow[t]{3}{*}{ Mean } \\
\hline & & \multicolumn{2}{|c|}{ Aug-Sept } & \multicolumn{2}{|c|}{ Sept-Oct } & \multicolumn{2}{|c|}{ Oct-Nov } & \multicolumn{2}{|c|}{ Nov-Dec } & \\
\hline & & Range & Mean & Range & Mean & Range & Mean & Range & Mean & \\
\hline 1. & Incubation period (days) & $3.00-4.00$ & 3.40 & $3.00-4.00$ & 3.20 & $3.00-4.00$ & 3.40 & $3.00-4.00$ & 3.20 & 3.30 \\
\hline \multirow{7}{*}{2.} & Larval period (days) & $13.00-19.00$ & 16.46 & $14.00-20.00$ & 16.98 & $14.00-21.00$ & 17.22 & $14.00-21.00$ & 17.24 & 16.97 \\
\hline & I instar & $2.00-3.00$ & 2.70 & $2.00-3.00$ & 2.90 & $2.00-3.00$ & 2.90 & $2.00-3.00$ & 2.80 & 2.80 \\
\hline & II instar & $2.00-3.00$ & 2.40 & $2.00-3.00$ & 2.50 & $2.00-3.00$ & 2.60 & $2.00-3.00$ & 2.50 & 2.50 \\
\hline & III instar & $2.00-3.00$ & 2.10 & 2.00 & 2.00 & 2.00 & 2.00 & $2.00-3.00$ & 2.30 & 2.10 \\
\hline & IV instar & 2.00 & 2.00 & $2.00-3.00$ & 2.10 & 2.00 & 2.00 & 2.00 & 2.00 & 2.00 \\
\hline & $\mathrm{V}$ instar & $2.00-3.00$ & 2.60 & $2.00-3.00$ & 2.70 & $2.00-3.00$ & 2.70 & $2.00-3.00$ & 2.80 & 2.70 \\
\hline & VI instar & $3.00-5.00$ & 4.20 & $4.00-6.00$ & 4.60 & $4.00-8.00$ & 5.30 & $4.00-7.00$ & 5.50 & 4.90 \\
\hline 3. & Pupal period (days) & $7.00-11.00$ & 8.36 & $8.00-11.00$ & 9.05 & $8.00-11.00$ & 9.21 & $8.00-12.00$ & 9.24 & 8.96 \\
\hline 4. & Pre-oviposition period (days) & $3.00-5.00$ & 3.21 & $2.00-5.00$ & 3.30 & $3.00-4.00$ & 3.31 & $4.00-5.00$ & 4.06 & 3.47 \\
\hline 5. & Oviposition period (days) & $2.00-4.00$ & 2.92 & $3.00-4.00$ & 3.16 & $2.00-4.00$ & 2.59 & $2.00-4.00$ & 3.18 & 2.96 \\
\hline 6. & Post-oviposition period (days) & $4.00-7.00$ & 5.80 & $5.00-7.00$ & 6.17 & $4.00-9.00$ & 6.25 & $5.00-8.00$ & 6.33 & 6.13 \\
\hline 7. & Female adult longevity (days) & $9.00-16.00$ & 12.12 & $10.00-16.00$ & 12.97 & $9.00-17.00$ & 13.10 & $11.00-17.00$ & 13.83 & 13.00 \\
\hline 8. & Male adult longevity (days) & $8.00-12.00$ & 10.57 & $7.00-12.00$ & 10.58 & $8.00-13.00$ & 10.87 & $7.00-14.00$ & 10.66 & 10.67 \\
\hline \multirow[t]{3}{*}{9.} & Total life cycle (days) & $33.00-44.00$ & 37.24 & $32.00-48.00$ & 37.63 & $34.00-48.00$ & 37.81 & $34.00-51.00$ & 38.06 & 37.68 \\
\hline & Female & $33.00-44.00$ & 38.50 & $37.00-48.00$ & 39.84 & $35.00-48.00$ & 40.26 & $37.00-51.00$ & 41.84 & 40.11 \\
\hline & Male & $33.00-40.00$ & 36.07 & $32.00-42.00$ & 36.11 & $34.00-41.00$ & 36.18 & $34.00-42.00$ & 36.26 & 36.15 \\
\hline 10. & No. of eggs/female & $995-2287$ & 1840 & $750-2065$ & 1629 & $915-2126$ & 1638 & $850-1935$ & 1541 & 1662 \\
\hline
\end{tabular}


Table.2 Morphometric data of S. frugiperda

\begin{tabular}{|c|c|c|c|c|}
\hline S. No. & \multicolumn{2}{|c|}{ Life stages } & Range (mm) & Mean \pm SD $(\mathrm{mm})$ \\
\hline \multirow[t]{6}{*}{1.} & \multirow[t]{6}{*}{ Larval length } & I instar & $1.5-2.0$ & $1.8 \pm 0.15$ \\
\hline & & II instar & $3.0-4.0$ & $3.5 \pm 0.45$ \\
\hline & & III instar & $5.5-6.5$ & $6.2 \pm 0.30$ \\
\hline & & IV instar & $9.0-10.5$ & $9.7 \pm 0.55$ \\
\hline & & V instar & $15.0-18.0$ & $16.8 \pm 1.08$ \\
\hline & & VIinstar & $32.0-36.0$ & $33.5 \pm 1.30$ \\
\hline 2. & \multicolumn{2}{|l|}{ Pupal length } & $14.0-19.0$ & $15.7 \pm 1.55$ \\
\hline \multirow[t]{7}{*}{3.} & \multicolumn{4}{|l|}{ Adult } \\
\hline & \multirow[t]{3}{*}{ Male } & Body length & $14.0-17.0$ & $15.8 \pm 1.03$ \\
\hline & & Wing length & $12.5-15.0$ & $13.7 \pm 0.85$ \\
\hline & & Wing span & $29.0-35.0$ & $31.7 \pm 2.05$ \\
\hline & \multirow[t]{3}{*}{ Female } & Body length & $13.0-17.0$ & $15.0 \pm 1.22$ \\
\hline & & Wing length & $12.0-15.0$ & $13.1 \pm 0.75$ \\
\hline & & Wing span & $29.0-34.0$ & $30.8 \pm 1.85$ \\
\hline
\end{tabular}

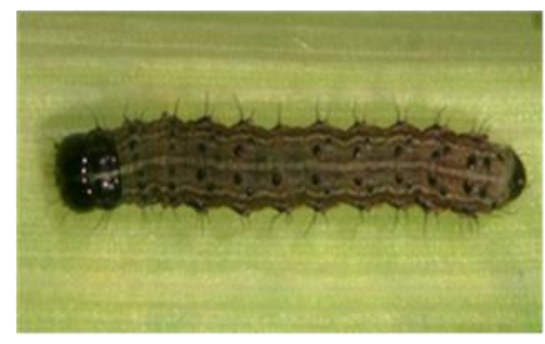

(a)

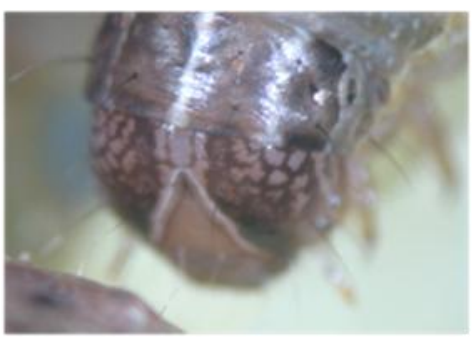

(b)

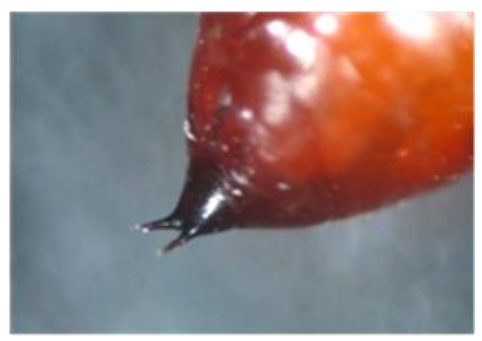

(c)

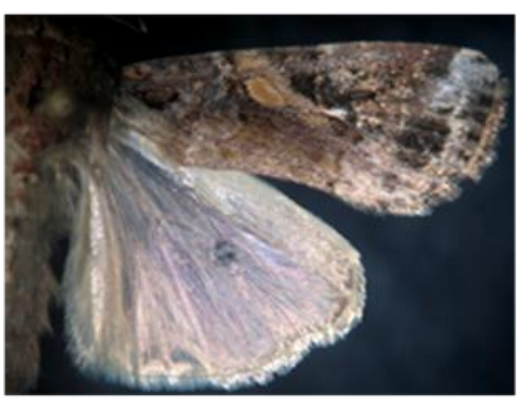

(d)

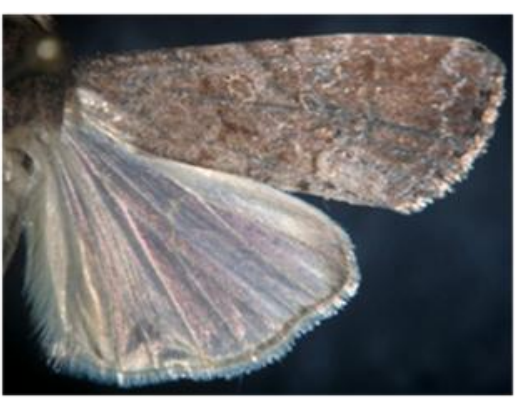

(e)

Fig.1 (a) Arrangement of spots on the larval body, (b) inverted Y shape on larval head, (c) pupa with 2 spines, (d) wings of male moth and (e) wings of female moth 


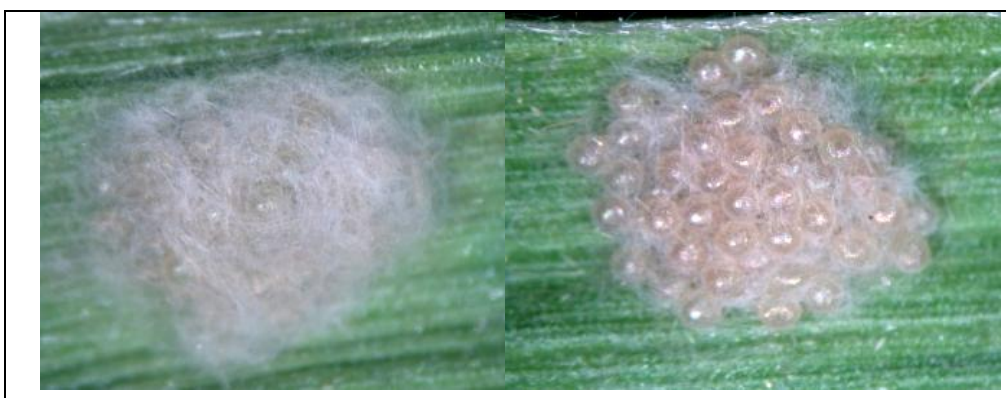

Fig.2 Egg mass of S. frugiperda

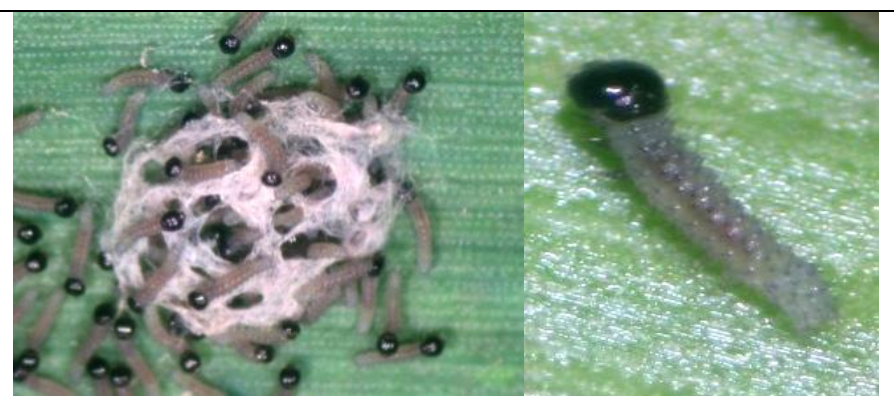

Fig.3 I instar larvae
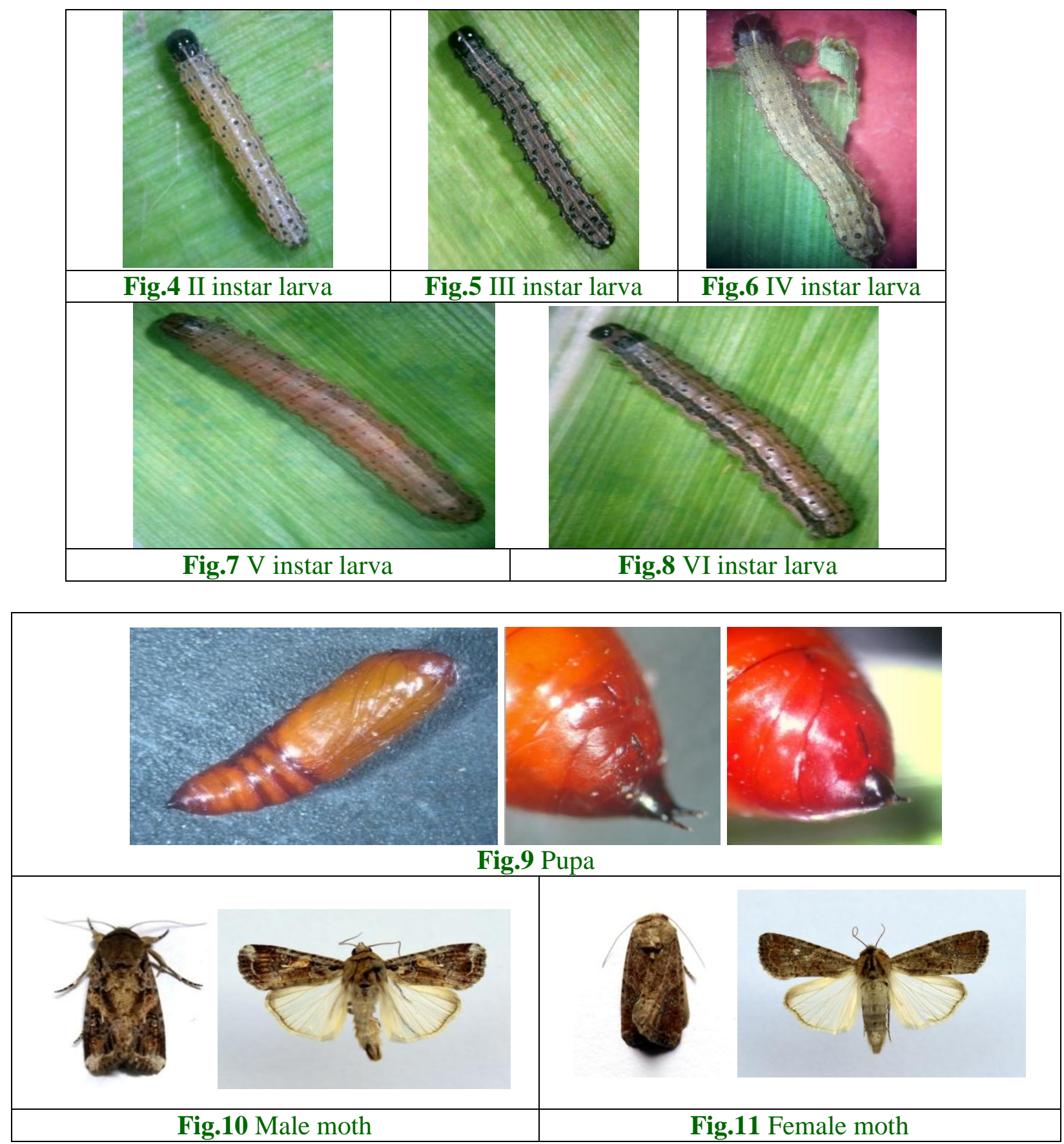
The mean development time of the $6^{\text {th }}$ larval instar was 4.9 days (Table 1). The total larval period completed in a mean duration of 16.97 days (Table 1).

\section{Pupa}

The freshly laid pupae of $S$. frugiperda were orange-brown in appearance and changed to dark reddish brown colour with time. The male and female pupae were also distinguishable based on the distance between their genital and anal opening slots. In males, this distance was less whereas in females it was more (Fig. 9). The mean pupal period was recorded to be 8.96 days (Table 1).

\section{Adult}

The adult of $S$. frugiperda is a small to medium sized moth. Sexual dimorphism was clearly evident (Fig. 10 and 11). The observations reveal that female moths lived more than the male moths. The mean adult longevity of female and male moths was 40.11 days and 36.15 days, respectively. The mean pre-oviposition, oviposition and post oviposition period was $3.47,2.96$ and 6.13 days, respectively. The average total life cycle of male and female was 36.15 and 40.11 days, respectively.

The results are in close conformity with earlier findings of Deole and Paul (2018), Bhavani et al., (2019), Manjula et al., (2019) and Malo and Hore (2020). Other morphometric data recorded is also presented in Table 2.

The present study provides the basic information about the biology and morphology of fall armyworm on maize. The research findings conclude that the pest takes about more than a month's time to complete its life cycle on maize, has a high fecundity rate and under favorable conditions it can multiply at a much faster rate. So, the main focus must be on formulating a suitable and feasible IPM module for FAW and spreading awareness among the farmers about its life cycle, inspection and the right time of employing management practices.

\section{References}

Bhavani, B., Sekhar, C. V., Varma, K. P., Lakshmi, B. M., Jamuna, P. and Swapna, B. 2019. Morphological and molecular identification of an invasive insect pest, fall armyworm, Spodoptera frugiperda occurring on sugarcane in Andhra Pradesh, India. Journal of Entomology and Zoology Studies, 7: 12-18.

CABI. Datasheet. 2019. Spodoptera frugiperda (fall armyworm). Invasive Species Compendium.

Chimweta, M., Nyakudya, I. W., Jimu, L., Mashingaidze, A.B. 2019. Fall armyworm Spodoptera frugiperda (J E Smith) damage in maize: management options for flood recession cropping small holder farmers. International Journal of Pest Management, https://doi.org/10.1080/09670874.2019. 1577514.

Deole, S. and Paul, N. 2018. First report of fall armyworm, Spodoptera frugiperda (J. E. Smith), their nature of damage and biology on maize crop at Raipur, Chhattisgarh. Journal of Entomology and Zoology Studies, 6: 219-221.

EPPO. 2015. Spodoptera littoralis, Spodoptera litura, Spodoptera frugiperda, Spodoptera eridania. EPPO Bulletin, 45: 410-444. Doi: 10.1111/epp.12258. Available from: http://www.eppo.int.

Goergen, G., Lava, K. P., Sagnia, B., Sankung, A. T. and Manuele, T. 2016. First report of outbreaks of the fall 
armyworm Spodoptera frugiperda (J. E. Smith) (Lepidoptera, Noctuidae), a new alien invasive pest in West and Central Africa. Plos One, 11: e0165632.

https://doi.org/10.1371/journal.pone.016 5632.

Malo, M. and Hore, J. 2019. The emerging menace of fall armyworm (Spodoptera frugiperda J. E. Smith) in maize: A call for attention and action. Journal of Entomology and Zoology Studies, 8: 455-465.

Manjula, K., Saheb, Y. P., Sudheer, M. J. and Rao, A. R. 2019. Studies on biology, feeding habits and natural enemies of fall armyworm, Spodoptera frugiperda, a new invasive pest in India. Journal of Entomology and Zoology Studies, 7: 1245-1250.

Pogue, M. A. 2002. A world revision of the genus Spodoptera Guenee (Lepidoptera: Noctuidae). Memoirs of the American Entomological Society, 43: 1-202.

Sharanabasappa, Kalleshwaraswamy, C. M., Ashokan, R., Mahadeva Swamy, H., Maruthi, M. S. and Pavithra, H. B. 2018. First report of fall armyworm, Spodoptera frugiperda (J. E. Smith) (Lepidoptera: Noctuidae) an alien invasive pest on maize in India. Pest Management in Horticultural Ecosystems, 24: 23-29.

\section{How to cite this article:}

Deepika Kalyan, M. K. Mahla, S. Ramesh Babu, R. K. Kalyan and Swathi, P. 2020. Biological Parameters of Spodoptera frugiperda (J. E. Smith) under Laboratory Conditions. Int.J.Curr.Microbiol.App.Sci. 9(05): 2972-2979. doi: https://doi.org/10.20546/ijcmas.2020.905.340 